\title{
RETRACTION
}

View Article Online

View Journal I View Issue

Check for updates

Cite this: RSC Adv., 2021, 11, 30040

DOI: 10.1039/d1ra90141a

rsc.li/rsc-advances

\section{Retraction: Boric acid in magnetized water: clean and powerful media for synthesis of 3,4- dihydropyrimidin-2(1H)-ones}

\author{
Vahid Khakyzadeh, ${ }^{\text {aa }}$ Ahmad Reza Moosavi-Zare, ${ }^{\text {b }}$ Sahra Sheikhaleslami, ${ }^{\text {a }}$ \\ Amir Ehsani, ${ }^{a}$ Salbin Sediqi, ${ }^{a}$ Mohammad Rezaei-Gohar ${ }^{b}$ and Zahra Jalilian ${ }^{c}$ \\ Retraction of 'Boric acid in magnetized water: clean and powerful media for synthesis of 3,4- \\ dihydropyrimidin-2(1H)-ones' by Vahid Khakyzadeh et al., RSC Adv., 2021, 11, 22751-22755. DOI: \\ 10.1039/D1RA03769B
}

We, the named authors, hereby wholly retract this $R S C$ Advances article. Although we maintain that the results obtained in distilled water are accurate, and believe that further experiments will confirm our conclusions, following discussions between the authors and the Royal Society of Chemistry, we have determined that the evidence presented regarding magnetised water in this paper is insufficient to support the conclusions and needs further investigation. We are therefore retracting the paper to maintain the validity of the scientific record. The Royal Society of Chemistry apologises for the fact that these concerns were not identified during the peer review process.

Signed: Vahid Khakyzadeh*,a ${ }^{*}$, Ahmad Reza Moosavi-Zare ${ }^{\mathrm{b}}$, Sahra Sheikhaleslami $^{\mathrm{a}}$, Amir Ehsani $^{\mathrm{a}}$, Salbin Sediqi $^{\mathrm{a}}$, Mohammad Rezaei-Gohar ${ }^{\mathrm{b}}$ and Zahra Jalilian ${ }^{\mathrm{c}}$

Date: $27^{\text {th }}$ August 2021 .

Retraction endorsed by Laura Fisher, Executive Editor, RSC Advances, 27 ${ }^{\text {th }}$, August 2021. 